\title{
SOBRE A CONSISTÊNCIA INTERNA DA ÉTICA DE HANS JONAS
}

On the intern consistency of Hans Jonas' Ethic

Guilherme T. M. Schettini Mestrando - UFRJ (Bolsa Capes)

RESUMO: Neste artigo, avaliaremos a consistência interna da Ética de Hans Jonas a partir das seguintes questões: i) Da anterioridade do Princípio Vida em relação ao Princípio Responsabilidade, e dos problemas que isso evita; ii) Do imperativo categórico de Jonas, e dos problemas que isso engendra; iii) Da suposta instrumentalização da vida humana pela Ética de Jonas; e iv) Do suposto caráter híbrido (deontológico e teleológico) da Ética de Jonas.

PALAVRAS-CHAVE: Hans Jonas; Consistência; Lógica.

\begin{abstract}
This article analyzes the consistency of Hans Jonas Ethics and is based on the following questions: (i) the antecedence of the Phenomenon of Life in relation to the Imperative of Responsibility, and the problems it avoids; (ii) the categorical imperative of Jonas, and the problems it engenders; (iii) the supposed instrumentation of human life by Jonas's Ethics; and (iv) the supposed hybrid character (deontological and teleological) of the Ethics of Jonas.
\end{abstract}

KEYWORDS: Hans Jonas; Consistency; Logic.

\section{APRESENTAÇÃO}

Tendo em vista as questões abordadas no curso Filosofia Social $I I^{1}$ e, é claro, a nossa formação em Filosofia, que, a despeito de genérica, tem dado ênfase na chamada Filosofia Analítica, pretendemos analisar aqui, sob quatro aspectos distintos, a consistência interna da Ética de Hans Jonas.

Por consistência interna de uma dada teoria entendemos a propriedade lógica que nos impede de chegar a conclusões contraditórias com os postulados da teoria dada. No caso da Ética de Jonas, os seus postulados (ou, em um linguajar menos técnico, os seus pilares)

\footnotetext{
${ }^{1}$ Curso oferecido pela professora Sarah Moura no Instituto de Filosofia e Ciências Sociais da UFRJ, entre outubro de 2015 e março de 2016.
} 
mais evidentes são o Princípio Vida e o Princípio Responsabilidade. Portanto, se é o caso de não sermos conduzidos, a partir dos pilares da Ética de Jonas, a nenhuma proposição falsa, vale dizer, negadora de algum desses pilares, estamos diante de uma teoria consistente (ou, o que é o mesmo, de uma teoria provida de correção lógica); se, ao contrário, a alguma dessas proposições "problemáticas" somos conduzidos, deparamo-nos com um caso de inconsistência lógica.

De antemão, é necessário precaver o leitor para a insuficiência deste trabalho. Ainda não estabelecemos um contato mais amplo com a obra de Jonas (a bem da verdade, o que sabemos desse filósofo se deve à esclarecedora Da ontologia da vida a uma ética para a civilização tecnológica, de Sarah Moura (Cf. MOURA)), pelo que não podemos, com o mínimo de bom senso, asseverar a consistência ou a inconsistência de sua teoria, pelo menos de uma forma que pareça geral e definitiva. Ademais, ainda que dispuséssemos de todo o conhecimento que possa haver sobre este autor, não é de nosso feitio proclamar veredictos dessa ordem.

Os nossos propósitos são, inversamente, muito modestos. Restringiremos a atenção a quatro questões que nos foram suscitadas no decorrer do curso e da leitura do texto de Sarah. São elas: i) Da anterioridade do Princípio Vida em relação ao Princípio Responsabilidade, e dos problemas que isso evita; ii) Do imperativo categórico de Jonas, e dos problemas que isso engendra; iii) Da suposta instrumentalização da vida humana pela Ética de Jonas; e iv) Do suposto caráter híbrido (deontológico e teleológico) da Ética de Jonas. É apenas sobre estas questões (que dão título a cada um dos itens da seção seguinte) que julgamentos do tipo "isto é consistente" ou "isto é inconsistente" irão incidir neste trabalho (especificamente, na seção das considerações finais).

Se, no entanto, são estas questões pertinentes ou não à obra de Jonas, e, por tabela, potencialmente comprometedoras ou não de sua teoria como um todo, isto fica a critério dos que melhor entendem desse autor.

\section{DESENVOLVIMENTO:}

2.1. Da anterioridade do Princípio Vida em relação ao Princípio Responsabilidade, e dos problemas que isso evita:

Pode-se dizer que os dois pilares metafísicos da Ética de Hans Jonas são o Princípio Vida e o Princípio Responsabilidade. Diante deste binarismo original, é natural 
perguntar se estes princípios são independentes ou dependentes, e, no último caso, se há uma hierarquia entre eles.

Pelo Princípio Vida, Jonas postula a "unidade psicofísica” da vida humana, isto é, a vida humana é concebida como a continuidade e a interdependência entre a mente e o organismo, e entre o organismo e a natureza. De imediato, o que nos interessa aí é a defesa de uma "visão sistêmica" da vida: com efeito, esta não pode ser concebida de uma forma separada da natureza.

De sua parte, o Princípio Responsabilidade postula o dever com o Ser (e talvez aqui possamos grosseiramente reduzir a palavra "Ser" à palavra "vida") em oposição ao nada, e isto implica o dever (da humanidade) de, por meio de suas ações, garantir as condições para uma vida autêntica no presente e no futuro. A ação responsável é vista, pois, como o requisito mínimo para a garantia da vida humana, e o ser humano é entendido como naturalmente orientado à preservação da vida (ainda que, muitas vezes - sobretudo da Era Moderna para cá -, pareça agir contra a sua própria natureza).

Aqui nos interessa saber se o Princípio Vida é anterior ao Princípio Responsabilidade, ou se este é anterior àquele (ou, ainda, se ambos são independentes). Ora, durante o curso que acabamos de realizar, uma das principais críticas dirigidas a Jonas foi a do suposto caráter antropocêntrico de sua Ética: Jonas estaria muito preocupado com a preservação da vida humana no futuro, mas pouco ou nada falaria da preservação da vida de todas as outras espécies sobre a Terra, pelo que seria no mínimo negligente, por exemplo, com o maltrato aos animais.

Isto nos parece uma confusão diretamente derivada do problema de que tratamos nesta seção. Se analisarmos o Princípio Responsabilidade isoladamente, talvez até estejamos autorizados a endossar o suposto antropocentrismo de Jonas: de fato, pelo menos no "imperativo categórico" (de que trataremos no item seguinte, mas que, por agora, podemos enunciar como "aja de tal maneira que os efeitos dos seus atos possibilitem a vida humana autêntica das gerações futuras") que norteia este Princípio, Jonas aparentemente preocupase apenas com a preservação da espécie humana.

Mas em que circunstâncias poderíamos analisar o Princípio Responsabilidade isoladamente? Ora, até onde nos permite a Lógica, em apenas duas: (i) se o Princípio Vida e o Princípio Responsabilidade fossem independentes; e (ii) se o Princípio Responsabilidade fosse anterior ao Princípio Vida. Em qualquer um desses casos, interpretaríamos a expressão "vida humana", tal como se encontra no "imperativo categórico" acima exposto, 
da maneira mais convencional possível: ela designaria a vida da espécie humana, vale dizer, do homo sapiens, e só desta.

Se, no entanto, o Princípio Vida fosse concebido como anterior ao Princípio Responsabilidade (em tempo: a "anterioridade" a que nos referimos é puramente lógica, isto é, não implica nenhuma supremacia de ordem prática de um princípio sobre o outro; talvez seja o caso de se pensar que ambos os princípios são igualmente relevantes para a Ética de Jonas), este mal entendido seria desfeito: neste caso, não poderíamos mais interpretar a expressão "vida humana", tal como exposta no "imperativo categórico", de uma maneira convencional; ela passaria a ter o significado preciso que encontramos no "Princípio Vida". E que significado é este? Ora, já vimos: a de vida humana como uma unidade psicofísica inseparável da natureza. Preservar a vida humana pressupõe e implica, portanto, preservar a natureza (com todas as espécies que ela contém).

Assim, parece-nos necessário conceder uma anterioridade lógica ao Princípio Vida sobre o Princípio Responsabilidade. A própria ordem em que Jonas os apresenta em sua obra já nos indica isso (o Princípio Vida foi primeiramente publicado em 1966; o Princípio Responsabilidade, em 1978). Ademais, o título da dissertação de Sarah, Da ontologia da vida a uma ética para a civilização tecnológica, nos autoriza a mesma interpretação.

2.2. Do imperativo categórico de Jonas, e dos problemas que isso engendra:

A máxima com que podemos sintetizar o Princípio Responsabilidade de Hans Jonas, "aja de tal maneira que os efeitos dos seus atos possibilitem a vida humana autêntica das gerações futuras", apoia-se, como vimos, em uma "visão sistêmica" da vida humana. Esta parece ser uma concepção de vida diretamente inspirada nas ideias do evolucionista Charles Darwin, que, grosso modo, defendia a tese de que a mudança das espécies naturais ocorria em consonância com o meio ambiente, em um processo denominado "seleção natural". Mas não será problemático fundar a Ética na Biologia?

As proposições da Biologia, como de qualquer ciência, são revisáveis. No Princípio Vida, o próprio Jonas nos informa das diferentes concepções de vida ao longo da História: à visão sistêmica e evolucionista dos contemporâneos, antecederam a visão mecanicista dos modernos, a visão criacionista dos medievais e a visão panvitalista dos antigos. Por que será a nossa visão a correta?

Em outras palavras, se as melhores teorias do passado foram refutadas, o que nos garante que um dia a nossa não será também refutada? Esta dúvida, conhecida na Filosofia 
como indução pessimista de Montaigne, não nos advertiria para o risco de se sustentar a Metafísica, que, por definição, é uma disciplina que trata de proposições eternas e universalmente válidas, nas ciências naturais cambiantes?

O ponto exato a que queremos chegar é o seguinte: será que não se afigura a Jonas a possibilidade de, com o passar do tempo, o próprio entendimento do que seja uma "vida humana autêntica" se transformar? E se, como advogam os mais entusiastas da Inteligência Artificial, a "vida humana" não passar de um algoritmo possível de ser reproduzido em um programa de computador? Ainda que hoje esta nos pareça uma tese extravagante, com que certeza podemos asseverar a sua falsidade absoluta, e, neste cenário hipotético, de que valeriam as preocupações de Jonas quanto à preservação da vida futura?

A resposta a todas estas questões só pode ser sincera: com efeito, Jonas é um filósofo do seu tempo (ou melhor, do nosso tempo, já que o seu tempo é o nosso), e não é mais pretensão de nossa Filosofia, ao contrário do que talvez tenha sido até a Idade Moderna, chegar ao conhecimento “certo, indubitável, eterno e imutável”. A Ética de Jonas, ao seguir a concepção sistêmica de vida, ainda que corra o risco de se apoiar em um terreno instável, a saber, o das crenças científicas, cumpre a sua função maior de oferecer princípios para as ações humanas, princípios estes que, diga-se de passagem, até agora não se revelaram problemáticos do ponto de vista lógico.

\subsection{Da suposta instrumentalização da vida humana pela Ética de Jonas:}

Pensemos, uma vez mais, no imperativo categórico de Jonas. Não haverá nesta asserção uma ideia instrumentalizada da vida humana, isto é, Jonas não estará concebendo a vida dos que vivem hoje (nós, nomeadamente) como um simples meio para a vida dos que virão no futuro?

Cumpre de imediato observar que certamente o indivíduo Hans Jonas pensava no ser humano como tendo um fim próprio, e na vida humana, por conseguinte, como tendo um fim próprio. A certeza com que asseveramos isso é resultante do curso que acabamos de realizar, e do contato mais amplo com as ideias do autor que tivemos nesse curso. Mas, olhando apenas para o imperativo categórico de Jonas (pois, para quem investiga a consistência de uma teoria, variáveis como o contexto não são relevantes, mas apenas as proposições dessa teoria - como nos ensinou Derrida, não há nada fora do texto), não será oportuno perguntar coisas como as do parágrafo precedente? 
Para por lenha nesta fogueira, e também aproveitando-nos de uma escrita mais madura do que a nossa, vejamos a posição de quem, pelo menos no terreno da Ética, diverge consideravelmente das ideias de Jonas, ainda que não faça referência direta a este filósofo: Miguel de Unamuno. Em seu Sentimento Trágico da Vida, nos diz Unamuno:

O homem é um fim, não é um meio. A civilização toda se endereça ao homem, a cada homem, a cada "eu". Que ídolo é este, chame-se Humanidade ou o que se queira, a que hão de se sacrificar todos e cada um dos homens? (...) Quem recebe o fruto desse sacrifício?

Os mesmos que nos falam desse sacrifício fantástico, dessa dedicação sem objeto, costumam também falar-nos do direito à vida. Mas o que é o direito à vida? (UNAMUNO. Del sentimiento trágico de la vida. Capítulo 1. Tradução nossa $\left.{ }^{2}\right)$

Ainda que, por diversas razões, nos sintamos muito mais atraídos pelo pensamento de Jonas do que pela filosofia de Unamuno, há algo no argumento deste filósofo que merece consideração, sobretudo se confrontado com a máxima de Jonas: trata-se da questão "quem recebe o fruto desse sacrifício?".

De fato, no caso da atual geração agir sempre com vistas à manutenção da vida autêntica no futuro, e isso exigirá, é evidente, a privação de muitas das coisas que ela se acostumou a ter, ou que poderia ter mas, em face da preocupação com o futuro, não terá, quem receberá o fruto desse sacrifício? Poder-se-ia apressadamente dizer: ora, as próprias gerações futuras serão as beneficiadas, dado que terão a sua existência autêntica garantida. Mas, alto lá: estas não terão também que seguir o imperativo de Jonas, e, portanto, não terão também que se sacrificar? (pois, ao que consta, não há uma data de validade para este imperativo). E as gerações seguintes, por sua vez, não terão que se sacrificar em nome das vindouras?

É fácil observar que a dinâmica anterior nos conduz ao infinito, e, infelizmente, parece deixar sem resposta a pergunta de Unamuno. Antes de esboçarmos alguma solução para este problema, mencionemos um último contra-argumento à Ética de Jonas, já bastante conhecido dos estudiosos desse autor: como falar em direitos para as gerações futuras (pensemos no direito à vida autêntica, para nos restringirmos ao imperativo categórico), se estas gerações concretamente não existem, isto é, se elas só existem enquanto possibilidade?

\footnotetext{
${ }^{2}$ Infelizmente, possuímos apenas uma versão digitalizada de Sentimiento Trágico de La Vida. Nesta versão, não consta quem digitalizou o livro, nem em qual edição se apoiou - isto é, o texto é apresentado diretamente e sem nenhuma referência à edição impressa. Desculpamo-nos, assim, pela ausência de indicação das páginas citadas, uma vez que tampouco encontramos o material digitalizado na internet, e informamos que a primeira publicação do livro ocorreu em 1913.
} 
Este é, sem dúvida, um agravante para os contra-argumentos anteriores: além de instrumentalizar a vida humana, o imperativo categórico de Jonas não estaria instrumentalizando-a para uma coisa que não existe e nem se sabe se existirá? Mas a questão dos direitos (ou melhor, da ausência deles) para as gerações futuras não é um problema de ordem lógica, ou seja, não diz respeito à consistência interna da teoria de Jonas, pelo que escapa à alçada deste trabalho (ademais, parece-nos de fácil solução: com efeito, agimos muitas vezes na vida com vistas a algo que ainda não existe, mas que supomos que existirá, e nem por isso deixamos de agir corretamente).

A questão que nos ocupa é, pois, a da suposta instrumentalização da vida humana. E aqui são duas as saídas possíveis: (i) podemos dizer que a preocupação com o bem das gerações futuras já implica, em certo sentido, a preocupação com o nosso próprio bem; vale dizer, ao agirmos com vistas à preservação da vida autêntica no futuro, já estamos resguardando a nossa própria vida autêntica; e (ii) podemos dizer que o apelo às gerações futuras é apenas um artifício psicológico utilizado por Jonas para sensibilizar os contemporâneos a fazer o que é necessário.

Quanto a este último ponto, cabe mais uma palavra: talvez seja o caso de se pensar que proposições do tipo "o planeta está sendo destruído", "a nossa vida está em perigo" etc. não convençam o público para a necessidade da ação comedida e razoável. Queremos dizer: talvez o ser humano não tenha amor próprio. Se isso for mesmo verdade, não há outra solução senão a adotada por Jonas: que apelemos, então, para o futuro de nossos filhos e descendentes.

2.4. Do suposto caráter híbrido (deontológico e teleológico) da Ética de Jonas:

No campo da Ética, há duas perspectivas teóricas que poderíamos chamar de clássicas (sem querer com isso, no entanto, remeter exclusivamente à filosofia grega): a perspectiva deontológica e a perspectiva teleológica. Com qual destas duas grandes perspectivas se aliará a Ética de Jonas?

Ora, vejamos primeiro o que diz cada uma dessas perspectivas. Em linhas gerais, a perspectiva deontológica se fundamenta na noção de dever, pelo que reúne se assim podemos falar, todas as "éticas dos deveres". Para estes sistemas, só há dois valores possíveis de verdade: o "certo" e o "errado". A perspectiva deontológica corresponde, 
portanto, à perspectiva das normas, e engloba todas as proposições do tipo "deve-se fazer X”, em que fazer X é “certo" e não fazer X é “errado”.

A perspectiva teleológica, por sua vez, se fundamenta na noção de fim (finalidade) e, muitas vezes, também na noção de bem, e tem como exemplo mais conhecido o utilitarismo de Stuart Mill. Para esta concepção, são vários os valores possíveis de verdade (digamos, o "excelente", o "melhor", o "razoável”, o "pior”, o “péssimo” etc.). A perspectiva teleológica corresponde, portanto, à perspectiva dos valores, e engloba todas as proposições do tipo "é melhor fazer X".

Se considerarmos uma vez mais (e pela última vez!) o imperativo categórico de Jonas, nos parecerá evidente alocar a sua Ética na perspectiva deontológica, pois agir com vistas à preservação da vida autêntica no futuro, antes de um valor, é um dever para Jonas. Além do mais, a proposição que expressa o imperativo categórico não comporta vários valores de verdade, mas apenas dois: o "certo" e o "errado" (é "certo" se preocupar com as gerações futuras, e é "errado" não fazer isso).

No entanto, considerando a obra de Jonas no seu todo, são vários os indícios de que a sua Ética comporta vários valores de verdade, e que se adéqua, portanto, a uma perspectiva teleológica. Por exemplo, ao criticar os regimes capitalista e socialista, atribuindo ao último um valor moral superior ao primeiro, mas, ao fim e ao cabo, condenando-o também pela sua obsessão com noções como o "progresso" e a "utopia", Jonas, a despeito de apontar para a insuficiência de ambos os sistemas no que se refere à preservação da autenticidade da vida futura, parece fazer uma distinção entre um "mal mais condenável” e um "mal menos condenável".

Estes matizes se manifestam de maneira ainda mais evidente nas medidas defendidas por Jonas para o combate à destruição do planeta, dentre as quais o desenvolvimento de fontes alternativas de energia e a diminuição do nível de consumo se destacam. Nestes casos, é de se presumir que, para a Ética de Jonas, quanto mais um Estado desenvolver alternativas energéticas e reduzir o nível de consumo, melhor será, e quanto menos o fizer, pior será, mas que não há um ponto fixo a partir do qual se diga: este Estado faz o "certo" ou este Estado faz o "errado".

Chegamos, assim, a uma aparente incoerência: a Ética de Jonas parece aliar-se ora à perspectiva deontológica, ora à perspectiva teleológica. Como sairemos desta emboscada?

Ora, sairemos de uma maneira muito simples: com efeito, se alguém nos abordasse com uma questão desse tipo, replicaríamos: “a rigor, o que nos obrigaria a 'encaixar' a Ética de Jonas em uma destas duas perspectivas? Qual seria o constrangimento lógico de que se 
elaborasse uma nova perspectiva na qual, para algumas proposições, fossem apenas dois os valores de verdade, e para as demais, fossem vários os valores de verdade? E, neste caso, a Ética de Jonas não seria satisfeita? Ora, a sua dúvida, meu caro interlocutor, parece deveras artificial".

\section{CONSIDERAÇÕES FINAIS}

Volvidas todas as etapas anteriores, é hora de avaliar a consistência interna da teoria de Hans Jonas relativamente aos aspectos levantados. Examinemos, pois, se efetivamente neste trabalho fomos conduzidos a alguma contradição, ou se, ao contrário, a partir dos pilares da Ética de Jonas, todas as proposições daí derivadas coadunaram com estes pilares.

Quanto ao primeiro ponto, Da anterioridade do Princípio Vida em relação ao Princípio Responsabilidade, e dos problemas que isso evita, vimos que, se por algum descuido, considerássemos o Princípio Responsabilidade isoladamente, isto é, ignorando o Princípio Vida, talvez pudéssemos derivar daí a crença de que a Ética de Jonas está apenas preocupada com a preservação da autenticidade da vida humana, e, portanto, desinteressada na preservação do restante da natureza (em uma palavra, que a Ética de Jonas é antropocêntrica). Esta conclusão seria, sem dúvida, contraditória com o Princípio Vida (caso o considerássemos depois), pelo que poderíamos atestar a inconsistência da teoria de Jonas. Ora, mas não há nada que nos autorize a considerar o Princípio Responsabilidade isoladamente (ou antes do Princípio Vida). A ordem com que estes princípios foram desenvolvidos pelo filósofo e o próprio título da dissertação de Sarah nos indicam o sentido inverso. Postulando a anterioridade do Princípio Vida em relação ao Princípio Responsabilidade, vale dizer, com esta precaução (pois a precaução também é bemvinda nas teorias), não chegaremos de forma alguma àquela conclusão contraditória.

No segundo item, Do imperativo categórico de Jonas e dos problemas que isso engendra, não chegamos a apontar, a bem da verdade, para nada que pudesse comprometer a consistência da Ética de Jonas. A questão que nos ocupou ali foi a de uma possível mudança de um paradigma das ciências biológicas, nomeadamente da teoria evolucionista de Darwin. No hipotético caso desta teoria ser suplantada por outra (como tantas vezes, na história das ciências, uma teoria foi suplantada por outra, numa dinâmica que não perdoou nem as melhores teorias do passado), e tendo em vista a inspiração direta do Princípio Vida no Evolucionismo de Darwin, a Ética de Jonas correria o risco de ficar defasada, sobretudo no entendimento do que seja uma "vida humana autêntica". Mas, há aqui que admitir, este 
seria apenas um problema de ordem prática; em termos estritamente lógicos, não é relevante se uma teoria filosófica é ou não "antenada" com as crenças científicas do momento.

Uma questão mais grave, no entanto, foi levantada em Da suposta instrumentalização da vida bumana pela Ética de Jonas. Com efeito, para que entendamos bem o problema, é primeiro preciso supor que, somado ao Princípio Vida e ao Princípio Responsabilidade, o que aqui chamaremos de Princípio de Toda Ética, a saber, "que o homem é um fim, não é um meio", constitui também um pilar da Ética de Jonas, ainda que implicitamente. Ora, se é assim, a proposição pela qual expressamos o imperativo categórico de Jonas é aparentemente negadora deste princípio (pois, por esta expressão - repetimos, por esta expressão -, o primeiro e único dever do ser humano é o de agir com vistas às gerações futuras, proporcionando-lhes condições para uma vida autêntica). Vimos, no entanto, que há pelo menos duas saídas possíveis para esta suspeita: a primeira é a de pensar que, ao agir com vistas às gerações futuras, o ser humano já estaria proporcionando o seu próprio bem (neste caso, ele continuaria sendo o seu próprio fim), e a segunda é a de supor que o apelo às gerações futuras é apenas um artifício psicológico utilizado por Jonas, artifício este que certamente veicula emoções, mas cujo valor cognitivo (e, portanto, teórico) deve ser desconsiderado.

Como o imperativo categórico de Jonas parece ser afeito às polêmicas, tratamos também dele na quarta seção, intitulada Do suposto caráter bíbrido (deontológico e teleológico) da Ética de Jonas. Mas esta questão revelou-se bastante artificial. Com efeito, caso considerássemos que toda teoria ética é ou deontológica ou teleológica, e que não há, portanto, nenhuma outra perspectiva sobre a qual possa se apoiar, o fato da Ética de Jonas possuir às vezes dois valores de verdade, às vezes vários valores de verdade, constituiria um real problema de inconsistência lógica. Mas não há por que considerarmos estes absurdos.

Então, perpassadas estas questões, não podemos concluir nada diferente disto: a teoria ética de Hans Jonas está longe de ingênua e, de fato, no que fomos capazes de analisar, nos parece consistente do ponto de vista lógico. A consistência interna, longe de ser uma propriedade apenas relevante para os sistemas formais da Lógica, é o requisito mínimo que toda teoria filosófica deve cumprir. O máximo a que pode aspirar uma teoria é, além de ser consistente, ser completa (isto é, além de só alcançar verdades, alcançar todas as verdades do domínio de que trata), mas há sérias dúvidas sobre a viabilidade disso (mesmo nas teorias matemáticas). Por isso, neste trabalho, restringimos a atenção à correção da teoria de Jonas, deixando para uma outra oportunidade a investigação de sua completude. 


\section{REFERÊNCIA}

MOURA, Sarah. Sobre a Ética do Futuro, de Hans Jonas. Dissertação de Mestrado. Rio de Janeiro: UFRJ, 2013. 